\title{
End-of-life management of waste automotive materials and efforts to improve sustainability in North America
}

\author{
R. Paul \\ Automotive Recycling Consultant, \\ Society of Automotive Engineers International, USA
}

\begin{abstract}
This paper will discuss the results of evaluating the North American automotive recycling infrastructure and vehicles processed, materials recycled, parts reused and management of waste materials including alternative treatments for automotive shredder residue. Data and other available information regarding these activities and material volumes will be presented to demonstrate the success of vehicle recycling. Vehicle recycling, component reuse and metal recovery is important to governments, vehicle manufacturers, suppliers, material recyclers, dismantlers and shredders. The highly efficient car recycling infrastructure serves to divert materials from landfill and recycle metals from a high volume consumer product and serves as an alternative source of low cost components for repair of vehicles that might otherwise be taken out of service. Although N. America has no single comprehensive, automotive specific law similar to Europe or Japan, there are myriad federal, state and local regulations that require vehicle pretreatment, fluid collection, separation of selected materials of concern and landfill restrictions.
\end{abstract}

Keywords: automotive recycling, vehicle recyclability, component reuse, material recycling, vehicle pre-treatment, shredder residue and sustainable development.

\section{Introduction}

Motor vehicles provide a huge benefit to society and many cultural and personal transportation advantages in developed and developing regions around the world. 
Approximately 800 million vehicles are in service in total, and new vehicle production is more than 70 million vehicles each year [1, 2]. Nearly 39 million vehicles go out of service each year mainly in three developed regions; Europe, Japan and North America [3]. Both Europe [4] and Japan [5] have recently enacted laws and regulations to improve the treatment of end-of-life vehicles, increase material recycling and to manage the treatment of automotive waste and certain substances of concern. In North America, there is no single comprehensive, automotive specific law similar to Europe or Japan, but there are myriad federal, state and local regulations which require vehicle pretreatment, fluid collection, separation of selected materials of concern and landfill restrictions on waste materials. The automotive recycling infrastructure is a large number of well developed, independent businesses that collect, process and manage vehicles that go out of service in an environmentally responsible manner and make available car parts for reuse and remanufacturing, facilitates the metal separation for recycling and manages the disposal of waste. In addition, the automobile manufacturing industry supports the recycling infrastructure with technical information, design for environment programs, hazardous material reductions and other sustainable management efforts.

Automobile recycling is a component of sustainable development in the transportation industry. Sustainable development is a pattern of resource use that aims to meet human needs while preserving the natural environment, or put another way it is a broad term for efforts to meet the needs of today without compromising the ability of future generations to meet their own needs [6]. There are three aspects of sustainable development; environmental, social and economic. Each of these adds an important function to sustainability. Assessments of the automotive life cycle have shown that end-of-life disposal has the smallest environmental impact. Nonetheless, with the number of vehicles on roads expected to rise to 1.85 billion vehicles by 2030 and the scrap generated from cars taken out of service to be 3.65 billion tons [3], there is a strong incentive to properly manage these materials, reduce waste and lower emissions.

\section{Vehicle processing}

Processing of end-of-life or crash vehicles in North America is a mature, well established, effective infrastructure which accomplishes fluid collection, hazardous material segregation, part dismantling, used parts resale, and scrap metal recycling. The hierarchy of treatment includes pretreatment, dismantling, metal separation and residue treatment (Figure 1).

\subsection{Pretreatment}

One of the most important environmental steps in automotive recycling is the removal of fluids and separation of hazardous materials for proper management and recycling. Table 1 lists the fluids and other materials removed from vehicles. In a 2004 monitoring study of automotive recycling, 891,786 metric tons of pre-treatment fluids and materials were collected for processing and recycling from 12 million end-of-life vehicles (ELVs) [7]. 


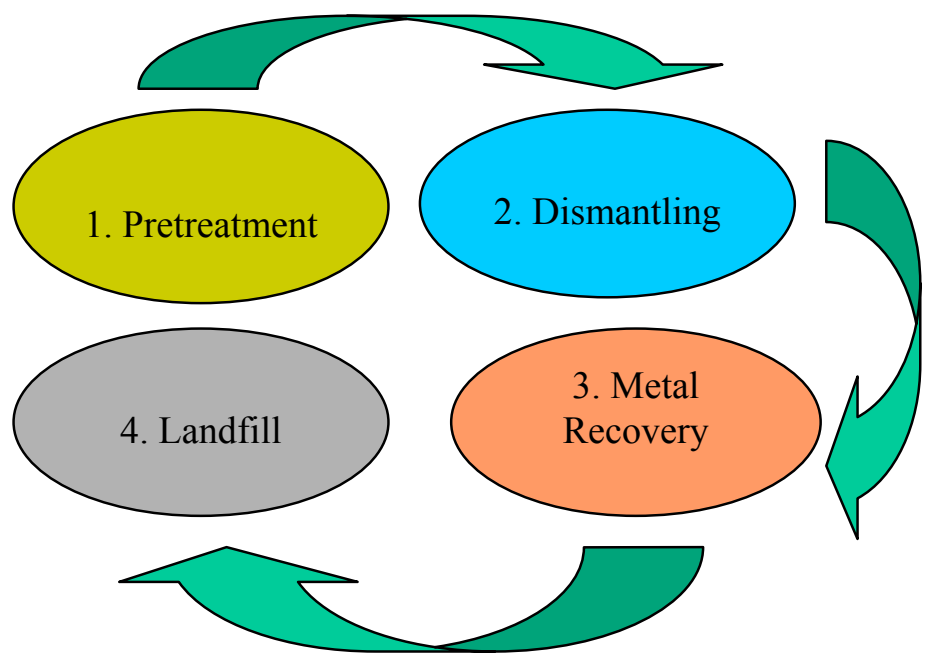

Figure 1: Vehicle processing.

Table 1: $\quad$ Vehicle pre-treatment.

- Fuel

- Engine oil

- Coolant

- Wiper fluid

- Transmission oil

- Brake fluid

- Power steering oil

- Refrigerant

- Batteries

- Tires

- Airbags

- Mercury switches

\subsection{Dismantling}

Vehicle dismantling is undertaken by full service dismantlers that resell the parts and components from newer cars to both wholesale and retail customers. The most common parts resold include the items listed in Table 2. Self service automotive recycling companies allow retail customers to remove parts from older salvage vehicles (generally 8 years and older) at discounted prices. Reuse plays an essential role in car recycling and illustrates the dominant role of the market based structure in the United States which is unique in its size compared to other developed regions around the world. The 2004 monitoring study [7] 
estimated 42,000 metric tons of used parts (non-metal portion) sold by full service dismantlers, from $40 \%$ of the 12 million ELVs. In addition to parts and components resale, dismantlers also collect parts for remanufacturing, generically called "cores" (cash on return parts). Remanufacturing is a second life for products that benefits both the environment and public by providing a low cost option for parts replacement [8]. Table 3 lists the most common cores, which includes both mechanical and crash parts.

Table 2: $\quad$ Parts collected for resale.

- Wheels

- Engines

- Transmissions

- Doors

- Bumpers

- Compressors

- Headlamps

- Radiators

- Fenders

- Front assembly

- Rear assembly

Table 3: $\quad$ Cores collected for remanufacturing.

- Engines

- Transmissions

- Brake calipers

- AC Condensers

- Starters

- Power Steering racks

- Bumpers

- Wheels

\subsection{Metal separation}

Remaining sections of vehicles after pretreatment and parts removal are crushed, baled or otherwise compacted at full and self-service recycling facilities and transported to automotive shredding facilities for processing in large hammer mills to separate metals from plastics, glass, rubber, fabric and other nonmetal materials. There are approximately 200 automotive shredders in operation in N. America. Ferrous metals are separated magnetically and nonferrous metals are separated by eddy current technology, often multiple times. The quantity of metal recycled from end-of-life vehicles is a result of the technology available and the extent to which the technology is used in the scrap processing industry. The collection efficiency of ferrous metals is generally accomplished by 
magnetic separation and estimated to be 96-98\% [9]. The use of eddy current induction, used for over 100 years in the design of electric motors, dynamos and transformers, has more recently been applied to nonferrous metal separation at shredding facilities and report efficiency of up to $95 \%[10,11]$. Sorting metals by hand is also used to increase the collection of these most valuable materials. In 2004, 12.5 million metric tons of metals (iron, steel, aluminum, copper, stainless steel, magnesium, etc.) were collected from 12 million vehicles that went out of service in that year [7].

\subsection{Landfill}

After shredding and metal separation, the remaining material, designated shredder residue (SR), is generally not further processed or separated in $\mathrm{N}$. America and the majority is sent to landfills. Often, landfills in the U.S. accept shredder residue as alternative daily cover (ADC) for landfills. ADC is required daily treatment for landfills to control vectors, fires, odor, blowing litter, and scavenging. There are a number of research efforts, pilot projects and emerging technologies that are being developed and show considerable promise for commercial application to separate non-metals for recycling. These are discussed in more detail below. Table 4 lists the composition of shredder residue.

Table 4: $\quad$ Shredder composition.

$\begin{array}{ll}\text { Plastics - } & 38 \% \\ \text { Rubber - } & 21 \% \\ \text { Glass - } & 12 \% \\ \text { Fluids - } & 12 \% \\ \text { Other - } & 15 \% \\ \text { r, foam, fabric, dirt, wood) }\end{array}$

Some small scale projects to further separate materials of value in shredder residue are in place and other programs with more significant resources are committed to various projects, across the country, to separate plastics, seat foam, capture additional metals or create fuels through mechanical separation, X-ray technology, or gasification and pyrolysis, as well as other technologies still under development [12-17]. The goal is to collect remaining metals, use other material as fuel or filler and isolate materials for recycling.

For example, technology is under development to treat shredder residue with variable frequencies of microwave radiation to produce oil and gas for energy recovery. The microwaves gasify the materials - a process also known as "cracking the hydrocarbon chain" - and convert them into 80 percent light combustible gases, and 20 percent oil. The gas is then cycled in a closed-loop system to fuel the next round of material breakdown, without emitting any harmful waste [18]. The alternative renewable energy system delivers benefits in four ways: 
- Combustible gases and fluids to energy

- Approximately $65 \%$ reduction of land fill

- Additional metallic material captured

- Alternative energy tax credits

Another example is a five-year cooperative research agreement ending this year that brought together the U.S. Department of Energy's Argonne National Laboratory, the American Plastics Council and the Vehicle Recycling Partnership of USCAR, a consortium of DaimlerChrysler Corp., Ford Motor Co. and General Motors Corp. The agreement enhanced recycling technology developed at Argonne to create a cost-effective process for recycling shredder residue from end-of-life vehicles. Argonne's new pilot facility incorporates two processes; the first is a bulk separation process that separates shredder residues into four categories: fines (iron oxides, other oxides, glass and dirt), polyurethane foams, a mixed plastics concentrate of polymers (polypropylene, polyethylene, ABS, nylon, PVC, polyester, and other materials) and residual metals. The second process is a fully continuous plastics separation system that demonstrates the selective recovery of specific plastics from the mixed plastics concentrates produced by the bulk separation process. The separation facility has a series of six separation tanks. The chemistry of the solutions in each tank controls the separation effectiveness of the overall process [19].

The Vehicle Recycling Partnership (VRP) and its partners have also identified a new recycling process that can convert the organic material in automotive shredder residue into a fuel oil. The Thermal Conversion Process (TCP) developed by Changing World Technologies (CWT) may make it possible to convert this waste into useful products. This process converts hydrocarbons and other organic materials into marketable oils and specialty chemicals for potential industrial and commercial use. Early research has demonstrated the ability to take shredder residue and convert it into a light diesel oil, syngas, and carbon. While the process has proven to be technically feasible, it will be important to learn whether the CWT process could handle raw shredder residue without any pre-processing [20].

\section{Other material management}

\subsection{Tire recycling}

Reuse, recycling and recovery of vehicle tires has improved dramatically in the U.S. due to sustained efforts by the Scrap Tire Management Council and individual state abatement programs, with the support of the rubber industry and tire producers. In 2005, the number of automotive and truck tires that went out of service was estimated to be approximately 299 million tires [21]. Over $86 \%$ of these tires (259 million) were diverted from landfill for reuse, recycling or energy recovery. This represents an 8 -fold increase in landfill diversion for tires since 1990. Tire stockpile abatement since 1990 has also been very successful and achieved an $81 \%$ reduction in tire piles around the country. Stockpiles are 
an environmental concern because of the potential for fire, rodent infestation and mosquito breeding.

The three major markets for scrap tires are tire derived fuels, civil engineering and crumb rubber. Other uses for discarded tires include agriculture, fuel for steel making in electric arc furnaces and about $2 \%$ are exported. See Figure 2 below.

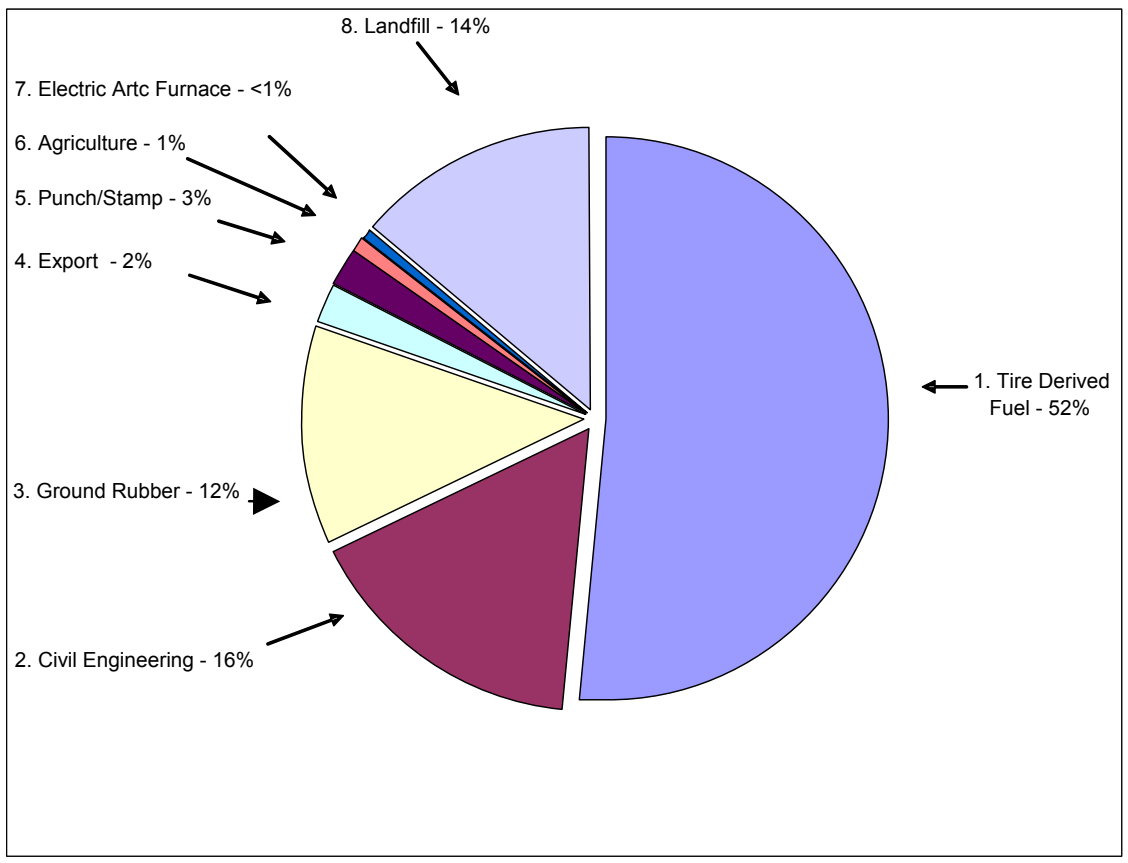

Figure 2: 2005 U.S. scrap tire disposition.

\subsection{Plastics recycling}

Major plastic components in automobiles are bumpers, fuel tanks and instrument panels. Research has been undertaken among several organizations to identify alternative treatments for these large plastic portions, which are currently a major constituent of shredder residue and are disposed as landfill. Plastic fuel tanks have been studied as an alternative fuel source [22], but collection and transportation costs represent major obstacles to development of a successful infrastructure. Bumpers and instrument panels, as well as other automotive plastics, have similar challenges for large scale material recycling which also include technology availability and limited markets [23]. Many small scale projects for automotive plastics recovery and recycling are in place regionally, which collect and process various plastic materials from ELVs, including remanufacturing lightly damaged bumpers for reuse, recycling scrap bumpers into non-automotive applications, recycling plastic casing of automotive batteries 
into new battery casings, recycling radiator end caps into non-automotive applications, and recycling plastic fuel tanks into non-automotive applications.

\section{Conclusions}

- U.S. dismantlers are very proficient at parts removal and resale and the infrastructure is very efficient at recycling high value and high volume materials.

- The introduction of sophisticated technology (e.g. eddy current) for metal separation allows higher levels of recovery of these readily recyclable materials. In addition, competitive and challenging business environments have caused higher levels of performance and improvements to automotive recycling.

- There are significant efforts by the U.S. automotive manufacturing industry and others to address the portion of end-of-life vehicles that is not currently recycled or otherwise not recovered. These efforts are driven by the need for sustainable management and to reduce shredder residue, which remains as the last significant component of automotive waste.

- Diversion of automotive tires from landfill and reduction of stockpiles has been very successful and accomplished an $86 \%$ recycling rate and reduction of stockpiles by $81 \%$ since 1991 .

- Automotive plastics are unlikely to be recovered and recycled in significant quantities until regulation limits their disposal in landfill or subsidies and other incentives drive the collection and treatment of these materials. Commercialization of SR treatment technology will also improve the diversion of automotive plastics from landfill.

\section{References}

[1] Automotive Digest, Automotive Information Network, World Automobile Population 2005 - 2020, www.automotivedigest.com, 2008

[2] International Organization of Motor Vehicle Manufacturers, 2007 Production Statistics, oica.net/category/production-statistics, 2008

[3] Winfield, P., Hutchinson, A. \& Pemberton, M., Whole Life Vehicle Waste Streams -A Global Perspective, Oxford Brookes University Press, 2007.

[4] Directive 2000/53/EC of the European Parliament and of the Council of 18 September 2000 on end-of-life vehicles, Official Journal of the European Communities, 21.10.2000.

[5] Japan ELV Recycling Law, July 2002.

[6] United Nations Report of the World Commission on Environment and Development, General Assembly Resolution 42/187, December 1987.

[7] Paul R., The Success of Vehicle Recycling in N. America, Proceedings of the 5th International Symposium on Recycling of Metals and Engineered Materials - LIGHT METALS, The Minerals, Metals \& Materials Society, February, 2007. 
[8] Paul, R., Remanufacturing - A second life for products, Recycling International, March 2008.

[9] Institute of Scrap Recycling Industries.

[10] Eddy Current Non-ferrous Metal Separators, Eriez Magnetics, SB780N, 2001.

[11] Eddy Current Separators Principles and Practices, Eriez Magnetics, SB501UK, 2002.

[12] Gesing, A., Assuring the Continued Recycling of Light Metals in End-ofLife Vehicles: A Global Perspective, Journal of Metallurgy, May 2004.

[13] From Auto Shredder to Blast Furnace, Metals Bulletin, April 14, 2004

[14] Winslow, G., et al, Recycling Shredder Residue Containing Plastics and Foam Using a Thermal Conversion Process, Proceedings of the Society of Automotive Engineers International Congress, 2005

[15] Sendijarevic, V. \& Sendijarevic, I., Chemical Recycling of Mixed Polyurethane Foam Stream Recovered from Shredder Residue into Polyurethane Polyols, Proceedings of the Society of Automotive Engineers International Congress, 2005.

[16] DEXRT - Effective Processing of Shredder Residue, Recycling International, September 2006.

[17] Argonne, Industry to Tackle End-Of-Life Vehicle Recycling, Recycling Today, February 2003.

[18] Auto Parts Become Fuel of the Future in World's First Emission-Free Recycling Machine, PRNewswire, 2007

[19] Argonne National Laboratory, Recycling Automotive Plastics is Profitable and Good for the Environment, www.anl.gov/Media_Center/News, November 2005.

[20] Winslow, G., et al., Scale-Up Study on Converting and Recycling Shredder Residue into a Fuel Oil, Proceedings of the Society of Automotive Engineers International Congress, March, 2006.

[21] Scrap Tire Markets in the U.S., 2005 Edition, Rubber Manufacturers Association, 2006.

[22] Paul, R.T., Raney, D., Harrell, M., Alternative Treatment of Plastic Fuel Tanks from End-of-Life Vehicles, Proceedings of the Society of Automotive Engineers International Congress, April 2007.

[23] Gallmeyer, W., Duranceau, C., Williams, R., Winslow, G., USCAR Field Trial for Automotive Polymers Recycling, Proceedings of the Society of Automotive Engineers International Congress, March 2003. 